\title{
Water-soluble compounds from the breadcrumb sponge Halichondria panicea deter attachment of the barnacle Balanus improvisus
}

\author{
Gunilla B. Toth*, Maria Lindeborg
}

Göteborg University, Department of Marine Ecology, Tjärnö Marine Biological Laboratory, 45296 Strömstad, Sweden

\begin{abstract}
Sessile invertebrates and algae are ubiquitous as hosts for a range of fouling organisms in marine benthic habitats. Fouling can sometimes impose negative fitness effects, and hosts may decrease the amount of fouling through production of chemical defenses. Waterborne chemical defenses may rapidly become diluted and should be released continuously in order to inhibit fouling; this process may be costly for the host. Therefore, it has been hypothesized that natural selection should favor the evolution of defense metabolites that stay on the host surface in aquatic environments. We investigated chemical deterrence of fouling in the marine sessile invertebrate Halichondria panicea (breadcrumb sponge), through both field observations and a series of laboratory bioassays. Natural populations of $H$. panicea had very few macrofouling organisms. Cyprid larvae of the barnacle Balanus improvisus were deterred from attaching to the substratum in the presence of water-soluble compounds that were rapidly exuded from the sponges both under laboratory conditions and in the field. Artificial substrata placed near H. panicea in the field received less fouling by barnacles than control substrata placed farther away from sponges. These results clearly show that $H$. panicea releases water-soluble compounds that deter attachment of $B$. improvisus. However, these compounds may not have evolved as a chemical defense against fouling in the sponges. H. panicea can release epidermal cell layers, and therefore the barnacles may have evolved an ability to recognize water-soluble compounds from the sponges in order to avoid attaching to unsuitable substrata.
\end{abstract}

KEY WORDS: Resistance $\cdot$ Cyprid larvae $\cdot$ Deterrence $\cdot$ Epibiosis $\cdot$ Fouling

\section{INTRODUCTION}

Sessile invertebrates and algae are ubiquitous in benthic marine habitats where competition for growing space can be severe (Dayton 1971). In situations of intense space competition, the living surfaces of other organisms provide additional space for attachment, metamorphosis, and growth, resulting in an interaction commonly referred to as epibiosis or fouling (we use 'attachment' instead of 'settlement' in this paper to avoid confusion; see Pawlik 1992). Marine fouling organisms may sometimes impose large negative fitness consequences on their hosts due to increased drag, structural damage, or increased attractiveness of the host to predators (reviewed by de Nys \& Steinberg 1999). In a situation where fouling decreases host fitness, natural selection should favor the evolution of host traits that inhibit or decrease fouling. Examples of such traits are production of spines, elaboration of tissue over settled organisms, sloughing of epidermal tissues, blade abandonment/proliferation, and production of mucus or bioactive secondary metabolites (e.g. Davis et al. 1989, Littler \& Littler 1999, Steinberg et al. 2001).

Chemical inhibition of fouling through the production of bioactive secondary metabolites has been found in a wide range of sessile marine invertebrates, as well as in seaweeds (reviewed by e.g. Davis et al. 1989, 
Pawlik 1992, Paul et al. 2006b). However, many of these studies tested the inhibitory effect of compounds extracted from within the tissues of organisms, and therefore the ecological relevance of these studies has been questioned (Steinberg et al. 2001, 2002). Compounds must be present at or near the surface of an organism at concentrations that negatively affect ecologically relevant fouling organisms in order to function as efficient chemical defenses against fouling. Compounds that are released from an organism in a turbulent marine environment will rapidly become diluted, and organisms must continuously produce and release the compounds in order to produce an effective concentration gradient. Therefore, selection for chemical defenses against fouling in aquatic habitats has been hypothesized to favor the evolution of surfacebound metabolites (Steinberg et al. 2001).

Attachment of invertebrate larvae or algal spores is inhibited both by surface-associated and exuded metabolites from seaweeds and sponges (e.g. Thompson 1985, Schmitt et al. 1995, Walters et al. 1996, Harder \& Qian 2000, Kubanek et al. 2002, Steinberg \& de Nys 2002 and references therein; Harder et al. 2004, Nylund et al. 2005, 2007, Dworjanyn et al. 2006, Paul et al. 2006a). However, to our knowledge, there are only 3 previous studies that directly compared the effect of exuded versus surface-associated metabolites on attachment success of invertebrate larvae (Schmitt et al. 1995, Dobretsov et al. 2006, Brock et al. 2007). Seawater conditioned with the green seaweed Caulerpa racemosa var. turbinata inhibited larval attachment of the tube-building polychaete Hydroides elegans, while hexane surface extracts from the seaweeds had no significant effect (Dobretsov et al. 2006). Similar results were found by Brock et al. (2007), who showed that seawater conditioned with the brown seaweed Fucus vesiculosus inhibited metamorphosis of Balanus improvisus, while dichloromethane/hexane surface extracts had no significant effect. In contrast, Schmitt et al. (1995) did not find negative effects of water collected close to the brown seaweed Dictyota menstrualis on the attachment of the bryozoan Bugula neritina, while surface rubbings of the seaweeds inhibited larval attachment.

The overall aim of the present study was to investigate if the temperate breadcrumb sponge Halichondria panicea has a chemical defense against fouling. This species has been shown to release epidermal cell layers in laboratory experiments, resulting in altered microfouling communities on the sponge surface (Barthel \& Wolfrath 1989). However, species of the genus Halichondria are rich in secondary metabolites (Harper et al. 2001), indicating that H. panicea may also be chemically defended (but see Thompson et al. 1985). Firstly, to investigate which species that naturally foul $H$. panicea, as well as the variation of fouling within and between sponge populations, we conducted an initial inventory of fouling organisms on sponge individuals in the field. We hypothesized that there would be a variation in the species composition and number of fouling organisms between different $H$. panicea individuals and populations. Secondly, we compared the antifouling effect of hexanesoluble surface extracts from $H$. panicea and seawater conditioned with sponges on the attachment success of the barnacle Balanus improvisus. We hypothesized that metabolites extracted from the surface of the sponges would deter attachment of barnacle larvae. However, because conditioned seawater, rather than hexanesoluble surface extracts, was shown to deter attachment of barnacle larvae, we continued to study the release of the water-soluble deterrent compounds both in the laboratory and in the field. We hypothesized that the compounds would be released rapidly in the laboratory and that seawater collected from natural populations of $H$. panicea in the field would deter attachment of cyprids. Finally, we conducted a correlative field experiment where we hypothesized that artificial substrata placed near $H$. panicea would exhibit less fouling by $B$. improvisus than control substrata placed farther away from the sponges.

\section{MATERIALS AND METHODS}

Study area and organisms. The experiments were performed outside the Tjärnö Marine Biological Laboratory (TMBL) on the west coast of Sweden. The study area is characterized by an archipelago with many small islands and islets. The tidal range is only about $20 \mathrm{~cm}$, but the mean water level can fluctuate a few meters depending on the prevailing air pressure and wind direction. Halichondria panicea is a common sponge species in the subtidal and low intertidal zone in the study area. It grows either as flat layers firmly adhered to the rock under stones or beneath large macrophytes, or as epiphytes on various species of red or brown algae in moderately exposed to exposed sites. The introduced barnacle species Balanus improvisus is common on rocky substrates, boat hulls, and on seaweed fronds in the intertidal zone (Wikström \& Pavia 2004, Brock et al. 2007) and occurs in the same habitat as $H$. panicea in the study area $(\mathrm{G}$. B. Toth pers. obs.). B. improvisus have a complex life cycle with several pelagic larval stages including a non-feeding cyprid stage, which is the larval stage responsible for finding a suitable substrate for attachment. B. improvisus cyprids use morphological, chemical, and hydrodynamic cues to find suitable substrates (Berntsson et al. 
2000, Dahlström et al. 2000, Larsson \& Jonsson 2006), and can be deterred from attaching to the substrate by secondary metabolites from seaweeds (Wikström \& Pavia 2004, Brock et al. 2007) and sponges (Sjögren et al. 2004).

Assessment of fouling on Halichondria panicea in the field. To monitor the natural fouling communities on Halichondria panicea individuals from different populations, an observational field study was performed in the archipelago outside TMBL in July 2006. Photographs of 10 haphazardly chosen $H$. panicea individuals at 5 randomly selected sites (i.e. a total of 50 photographs) were taken with a digital camera (Minolta DiMAGE Xt), and $10 \times 10 \mathrm{~cm}^{2}$ of each individual was monitored for macrofouling organisms using an image analyzing software (ImageJ). Because almost no fouling was discovered (see Results), data were not analyzed statistically.

Laboratory experiments with Balanus improvisus. To investigate if Halichondria panicea has a chemical defense against fouling, a series of laboratory bioassays using the barnacle Balanus improvisus were performed during July and August 2006. Because Halichondria release a large amount of organic substances when damaged (G. B. Toth pers. obs.), we used Halichondria individuals growing as epiphytes on red seaweeds (Chondrus crispus and Phyllophora sp.) in the experiments. Seaweeds and sponges were collected haphazardly at different sites outside the laboratory by removing the seaweeds from the substrate without damaging the sponges. The organisms were transported in coolers to the laboratory where they were kept in flow-through seawater until experiments started (within a few days of collection). Competent $B$. improvisus cyprid larvae were obtained from a laboratory culture (see Berntsson et al. 2000 for details).

The first experiment was designed to investigate if Halichondria panicea release water-soluble bioactive metabolites or if metabolites are associated with the surface of the sponge. One liter of filtered seawater (FSW, $0.22 \mu \mathrm{m}$ ) was conditioned with $100 \mathrm{ml} \mathrm{H}$. panicea individuals for $1 \mathrm{~h}$. The volume of the sponges and associated seaweeds was determined by water displacement in a graduated cylinder (the volume of the seaweeds was negligible compared to the sponge). The conditioned seawater (CSW) was filtered $(0.22 \mu \mathrm{m})$, and $10 \mathrm{ml}$ were transferred to each of 4 Petri dishes. Controls were prepared by adding FSW to 4 separate Petri dishes. Furthermore, H. panicea individuals with a surface area approximately corresponding to 4 Petri dishes were submerged in hexane and vortexed for $40 \mathrm{~s}$. This procedure has been used to successfully extract non-polar, surfacebound metabolites from seaweeds (de Nys et al. 1998, Nylund et al. 2007). The hexane was evaporated and the extract was re-dissolved in $4 \mathrm{ml}$ hexane. One $\mathrm{ml}$ surface extract was transferred to each of 4 Petri dishes and was evaporated by placing the dishes on a shaking table, thereby dispersing the extract evenly around the bottom and edges of the dishes. Solvent controls were prepared by adding $1 \mathrm{ml}$ hexane to 4 additional dishes and repeating the evaporation procedure. Ten ml FSW were added to the hexanetreated dishes. At the start of the experiment, 20 cyprid larvae were added to each dish $(\mathrm{n}=4$, a total of 16 dishes). The experiment was terminated after $4 \mathrm{~d}$ when the number of metamorphosed juvenile barnacles was counted in each dish. Attachment success was calculated as the percentage of barnacles fixed to the substratum and undergoing metamorphosis. Data were statistically analyzed with an orthogonal 2-way ANOVA using treatment and solvent as fixed 2-level factors.

When Halichondria panicea grows in close association to its red seaweed host it is impossible to remove the seaweeds without damaging the $H$. panicea tissues, which in turn results in a release of intracellular compounds to the surrounding water. Therefore, we designed an experiment to investigate if the bioactive metabolites found in the CSW in the previous experiment (see Results) were produced by the sponges or by the associated seaweeds. Twenty individuals of $H$. panicea growing as epiphytes on red seaweeds were sampled at haphazardly chosen sites outside TMBL and brought back to the laboratory. Their volume was determined as described above, and 10 sponges with associated seaweeds were placed individually in plastic containers $\left(\begin{array}{ll}1 & 1\end{array}\right)$ at a volumetric relationship of approximately $10 \mathrm{ml}$ sponge in $100 \mathrm{ml}$ filtered seawater. The pieces of seaweeds protruding from the sponge surface were removed with a pair of scissors, and the algal pieces from each of 10 sponge individuals were placed separately in 10 plastic containers (1 l $)$ containing $100 \mathrm{ml}$ filtered seawater. Controls were prepared by adding $100 \mathrm{ml}$ filtered seawater to 10 additional containers. The seawater was conditioned with the different treatments for $1 \mathrm{~h}$, after which $10 \mathrm{ml}$ from each container were filtered $(0.22 \mu \mathrm{m})$ and transferred to clean Petri dishes (i.e. a total of 30 dishes). Twenty cyprid larvae were added to each dish, and the number of metamorphosed larvae was counted after $4 \mathrm{~d}$. Attachment success was calculated as the percentage of larvae fixed to the substratum and undergoing metamorphosis, and data were statistically analyzed in a 1-way ANOVA with treatment as a fixed 3-level factor.

An additional experiment was designed to further investigate on which time-scale the bioactive compounds were released from Halichondria panicea. Twenty sponge individuals were collected from hap- 
hazardly chosen sites outside TMBL, brought back to the laboratory, and their volumes determined by water displacement in a graduated cylinder. Each sponge individual was placed in a separate $1 \mathrm{l}$ container at a volumetric relationship of 1:10 sponge:FSW. Ten $\mathrm{ml}$ of CSW were removed from 5 containers each after 15 , 30,45 , and $60 \mathrm{~min}$. Controls were prepared by conditioning FSW in 5 additional containers without $H$. panicea for $1 \mathrm{~h}$. The CSW was filtered $(0.22 \mu \mathrm{m})$ and transferred to separate Petri dishes. Twenty cyprid larvae were added to each dish immediately after transfer of the CSW, and the attachment success was determined after $4 \mathrm{~d}$ as described above. Data were statistically analyzed using a 1-way ANOVA with treatment as a fixed 5-level factor.

Finally, 2 experiments were performed to test if Halichondria panicea release bioactive metabolites in their natural habitat. Ten water samples were collected with plastic syringes $(10 \mathrm{ml})$ close $(1$ to $10 \mathrm{~mm}$ ) to the surface of different $H$. panicea individuals growing at approximately $1 \mathrm{~m}$ depth in the field. Control samples were collected at $1 \mathrm{~m}$ depth in the open water approximately $5 \mathrm{~m}$ from the sponges. The water samples were immediately transported on ice to the laboratory where they were added to individual Petri dishes and the barnacle attachment assay was repeated as described above. This experiment was repeated, with the only difference that the water samples were filtered $(0.22 \mu \mathrm{m})$ before transfer to the Petri dishes. Data from both experiments were statistically analyzed using $t$-tests.

Fouling on artificial substrata in the field. To further explore the ecological significance of the results found in the laboratory experiments, a correlative field experiment was performed in August 2006 to test if water-soluble metabolites from Halichondria panicea can decrease the attachment of Balanus improvisus in natural populations. A Plexiglas plate was attached with plastic cable ties to the base of a large brown seaweed (Laminara saccharina) at a depth of $1 \mathrm{~m}$ either close to (a few $\mathrm{cm}$ ) or far away (at least $1 \mathrm{~m}$ ) from $H$. panicea individuals growing as flat layers on the rock at 5 haphazardly chosen sites outside the TMBL $(n=2$, i.e. a total of 20 plates). However, because not all plates were found when the experiment was terminated after $2 \mathrm{wk}$, we had to exclude the factor site from the statistical analysis. Therefore, data on the number of $B$. improvisus on the plates at the end of the experiment were statistically analyzed using a $t$-test $(\mathrm{n}=5)$.

Prior to all statistical analyses, data were tested for homogeneity of variances using Cochran's test and transformed when required. Significant differences between mean values were statistically analyzed using the Student-Newman-Keuls (SNK) multiplecomparison test.

\section{RESULTS}

The observational field study showed that only a few individuals of Halichondria panicea had macroscopic epibionts (the sea anemone Metridium senile), although there was a rich abundance of other potential fouling organisms (e.g. barnacles, mussels, filamentous algae, bryozoans, and hydroids) present in the same habitat as $H$. panicea. No statistical analysis of the data was performed, and we concluded that $H$. panicea is relatively free from macrofouling in its natural habitat.

The hexane-soluble surface extract and conditioned seawater had different effects on cyprid attachment success, as shown by the statistically significant interactive effect of the factors treatment and solvent (ANOVA, $F_{1,12}=11.518, \mathrm{p}=0.005$ ). When means were compared with the SNK procedure, it was found that cyprid attachment success was significantly $\left(\mathrm{SNK}_{,} \mathrm{p}<\right.$ $0.05)$ lower in the FSW conditioned for $1 \mathrm{~h}$ with Halichondria panicea compared to control seawater (Fig. 1). However, there was no significant $(\mathrm{SNK}, \mathrm{p}>$ 0.05) negative effect of the hexane-soluble surface extract on the cyprid attachment success (Fig. 1).

There was a significant difference in attachment success of cyprids that were allowed to settle in water conditioned with Halichondria panicea and associated red seaweeds, seaweeds only, and controls (ANOVA, $\left.F_{2,27}=12.105, \mathrm{p}<0.001\right)$. There was no significant (SNK, $\mathrm{p}>0.05$ ) difference in attachment success be-

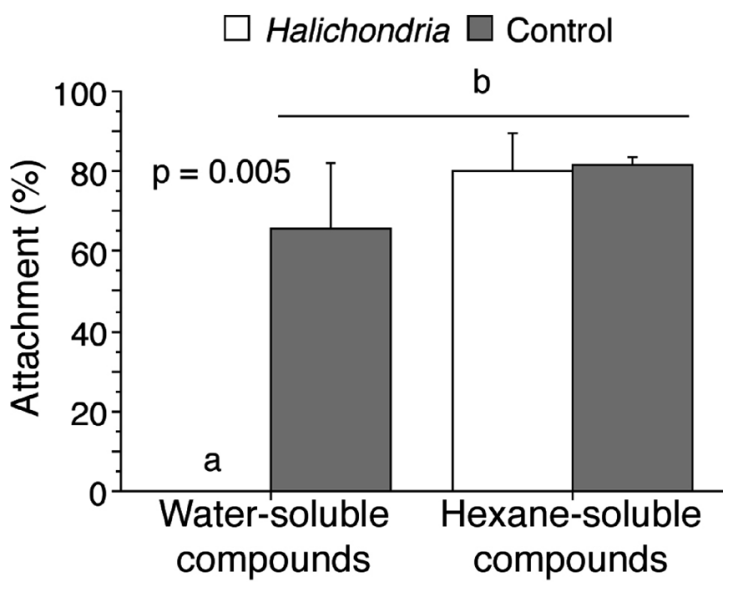

Fig. 1. Balanus improvisus. Attachment success (\%) of cyprid larvae presented to water-soluble compounds released after $1 \mathrm{~h}$ of conditioning with Halichondria panicea (water-soluble compounds), to metabolites extracted from the sponge surface with hexane (hexane-soluble compounds), or to the appropriate solvent controls. Letters above bars indicate significant differences between mean values based on the Student-Newman-Keuls multiple comparisons test (SNK, p < 0.05). Error bars show + SE $(n=4)$ 


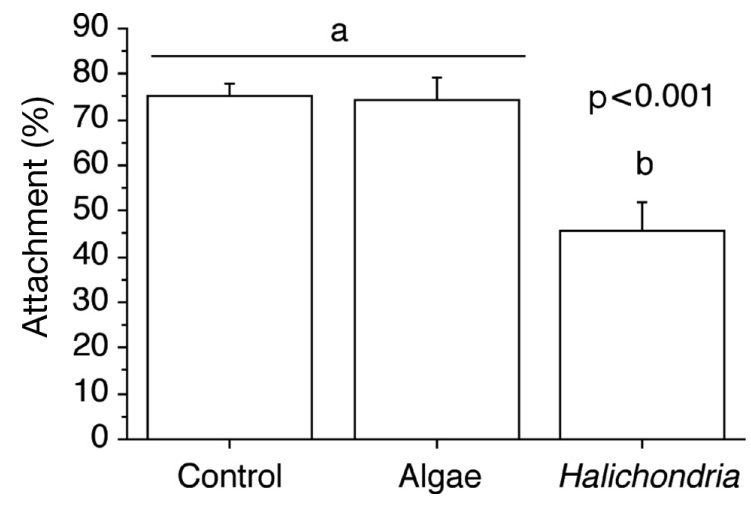

Fig. 2. Balanus improvisus. Attachment success (\%) of cyprid larvae in laboratory experiments with seawater conditioned for $1 \mathrm{~h}$ with Halichondria panicea and associated red seaweeds, seaweeds only, and controls. Letters above bars indicate significant differences between mean values based on the Student-Newman-Keuls multiple comparisons test (SNK, $p<0.05)$. Error bars show $+\mathrm{SE}(\mathrm{n}=10)$

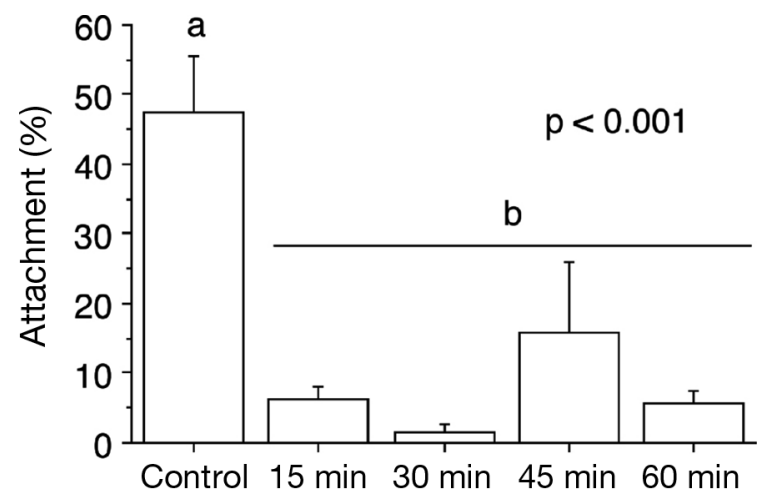

Fig. 3. Balanus improvisus. Attachment success (\%) of cyprid larvae in laboratory experiments with filtered seawater (control), or seawater conditioned for 15, 30, 45, and 60 min with Halichondria panicea. Letters above bars indicate significant differences between mean values based on the StudentNewman-Keuls multiple comparisons test (SNK, p < 0.05). Error bars show $+\mathrm{SE}(\mathrm{n}=5)$

tween cyprids allowed to settle in Petri dishes with conditioned water from red seaweeds and controls (Fig. 2). However, there was a significant decrease in attachment success of cyprids allowed to settle in the Petri dishes with conditioned seawater from Halichondria and associated red seaweeds (Fig. 2).

There was a significant effect of the factor treatment (ANOVA, $F_{4,20}=10.099, \mathrm{p}<0.001$ ) on cyprid attachment success when cyprids were allowed to settle in seawater conditioned with Halichondria panicea for different time periods. The CSW significantly (SNK, $\mathrm{p}<0.05)$ deterred attachment of Balanus improvisus cyprids after 15 min (Fig. 3), showing that the bioactive metabolites are rapidly released into the water.

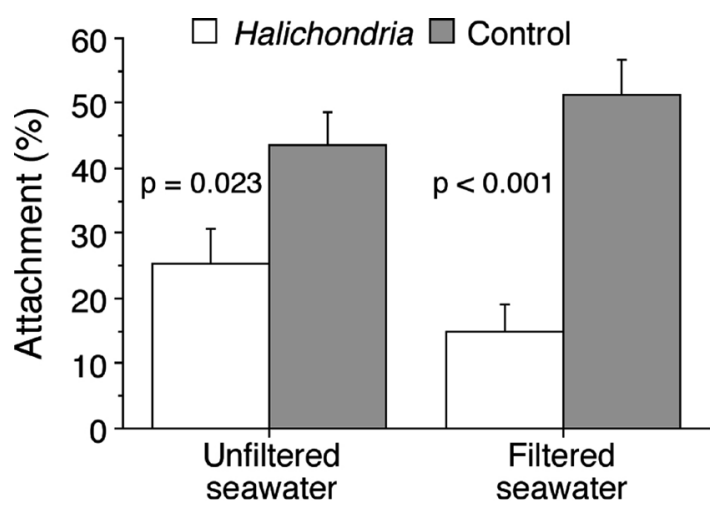

Fig. 4. Balanus improvisus. Attachment success (\%) of cyprid larvae in laboratory experiments with either unfiltered or filtered $(0.22 \mu \mathrm{m})$ seawater collected close to the surface of Halichondria panicea individuals (Halichondria) or $5 \mathrm{~m}$ from shore (control) in the field. Error bars show + SE $(n=10)$

Both unfiltered and filtered water samples collected close to Halichondria panicea individuals in the field had a significant ( $t$-test, unfiltered: $t_{1,18}=6.133, \mathrm{p}=$ 0.023; filtered: $t_{1,18}=28.751, \mathrm{p}<0.0001$ ) negative effect on the attachment success of Balanus improvisus compared to water sampled $5 \mathrm{~m}$ from the sponges (Fig. 4).

There was a significant difference in the number of Balanus improvisus that attached to the Plexiglas plates placed near or $1 \mathrm{~m}$ away from Halichondria panicea individuals in the correlative field experiment ( $t$-test, $\left.t_{1,8}=10.127, \mathrm{p}=0.013\right)$. Plates placed near $H$. panicea had $1.2 \pm 0.49$ barnacles (mean \pm SEM), while control plates had $5.2 \pm 1.16$ individuals.

\section{DISCUSSION}

Despite the ubiquitous occurrence of potential fouling organisms in the marine environment close to Halichondria panicea, the initial field survey showed that the sponge individuals were almost free from macroepibionts in natural populations, indicating that they have evolved traits that decrease or inhibit fouling. Results from laboratory bioassays showed that sponge individuals released water-soluble compounds that deterred attachment of the barnacle Balanus improvisus. The deterrent compounds were released quickly under artificial laboratory conditions, and were also found in effective concentrations near sponges in natural populations. However, the hexanesoluble surface extract did not have a significant effect on barnacle attachment. One explanation for these results may be that hexane, which is a non-polar solvent, did not sufficiently extract the wet surface of the sponges, and therefore no surface-bound metabolites were liberated. Therefore, we cannot rule out the pos- 
sibility that the sponges produce surface-bound metabolites that function as chemical defenses against fouling organisms, but that were not extracted by the method used in this study.

The ecological relevance of several previous studies on chemical defenses against fouling in marine organisms has been criticized because metabolites were extracted from within host tissues (e.g. Steinberg et al. 2001, 2002). Similar critiques can be raised toward most previous studies on the deterrent effects of watersoluble metabolites on potential fouling organisms (Walters et al. 1996, Harder \& Qian 2000, Lee \& Qian 2003, Dobretsov et al. 2004, 2006, Brock et al. 2007). These studies used seawater conditioned with host organisms in relatively small containers for long time periods ( 1 to $24 \mathrm{~h}$ ). The results from such experiments do not reflect a natural situation, and organisms may be induced to release unnaturally high concentrations of bioactive metabolites under artificial laboratory conditions. A somewhat more ecologically realistic approach was used by Harder et al. (2004), who collected water from seaweeds enclosed for $1 \mathrm{~h}$ in transparent plastic bags in the field. However, this procedure will change the hydrodynamic environment around the organisms, allowing a concentration build-up of metabolites that may not occur naturally. To conduct ecologically realistic tests of the inhibitory effect of exuded compounds, water should be sampled close to potential host organisms in natural populations and tested in bioassays using ecologically relevant bioassay organisms. To our knowledge, only 1 previous study has used this approach (Schmitt et al. 1995).

Another more ecologically realistic approach to study the effect of exuded metabolites on fouling organisms is to transplant artificial substrate in the field. In the correlative field experiment in our study, fewer Balanus improvisus were found on the Plexiglas plates placed near Halichondria panicea in natural populations compared to plates placed at least $1 \mathrm{~m}$ from sponges, corroborating the results from the laboratory experiments. A more rigorous approach was used by Dobretsov et al. (2004), who transplanted both sponges and artificial substrate in the field. They found that macrofouling communities developing on artificial substrate placed near Callyspongia pulvinata were negatively affected by the presence of sponges. These findings contradict the results from an earlier study, where small-scale flow regimes and patchy larval supply were shown to have a larger effect than exuded metabolites on the recruitment patterns of fouling organisms to artificial substrates placed close to 7 different sponge species (not including C. pulvinata) in the field (Bingham \& Young 1991). To our knowledge, these field experiments (Bingham \& Young 1991, Dobretsov et al. 2004, the present study), and the bioassays using seawater collected in natural populations of $H$. panicea in the present study, are the only studies that have tested the antifouling activity of unidentified sponge metabolites (waterborne or surface-associated) at natural concentrations against ecologically relevant epibionts (but see Kubanek et al. 2002, who quantified the concentration of triterpene glycosides in the surface layers of sponge individuals and concluded that they were sufficient to deter bacterial settlement and fouling).

The results that exuded metabolites deter attachment of epibionts are not in accordance with the hypothesis that chemical defenses against fouling in aquatic habitats should be surface-associated compounds (e.g. Steinberg et al. 2001). However, apart from production of chemical defenses, potential marine host organisms express other types of mechanisms to decrease fouling (e.g. Davis et al. 1989, Littler \& Littler 1999, Steinberg et al. 2001). Several of these traits (e.g. elaboration of tissue over settled organisms, sloughing of epidermal tissues, blade abandonment/ proliferation, and production of mucus) function as defenses by increasing the post-settlement mortality of the fouling organisms. If post-settlement mortality is high, which is true for many sessile marine invertebrates (Hunt \& Scheibling 1997), invertebrate larvae should be under a strong selection pressure to evolve mechanisms to recognize and avoid unsuitable substrata. For example, invertebrate larvae sense and respond to water-soluble chemical cues in order to avoid attaching to substrates near predators or competitors (e.g. Grosberg 1981, Young \& Chia 1981, Welch et al. 1997, but see Bullard et al. 2004). Therefore, exuded water-soluble metabolites could function as deterrents of attachment if they carry negative information about a substrate and/or environment. Halichondria panicea release epidermal cell layers (Barthel \& Wolfrath 1989), indicating that the postsettlement mortality of larvae attaching on this sponge species may be high, and that the surface of $H$. panicea is an unsuitable substrate for sessile invertebrates. Therefore, the negative effect of exuded compounds from $H$. panicea on Balanus improvisus attachment found in the present study could be explained by the selection being on the barnacle larvae to avoid an unsuitable substrate, rather than on the sponge to evolve a chemical defense against fouling.

\section{CONCLUSIONS}

There are still few studies on chemical inhibition of fouling that have adopted an ecologically relevant protocol to test the deterrent effect of metabolites available to larvae or propagules in natural populations. If 
the production of chemical defenses is costly in terms of host fitness, natural selection should favor the evolution of surface-associated chemical defenses against fouling (cf. Steinberg et al. 2001). However, we suggest that water-soluble metabolites, produced by the host or host-associated microorganisms, may also be common chemical attachment deterrents of marine fouling organisms when alternative morphological, chemical, or hydrodynamical defense strategies are present in the host. Seaweeds and sponges release water-soluble metabolites that deter or inhibit attachment or growth by sessile marine organisms, but it is not known if these species possess alternative antifouling mechanisms. A direct test of the proposed hypothesis remains to be performed.

Acknowledgements. We are grateful to all staff and students at Tjärnö Marine Biological Laboratory for their helpfulness and encouragement, especially J. Fahlström, A. Pehrsson, and J. Ulvås for assistance with laboratory experiments, and $\mathrm{H}$. Pavia for comments on an earlier version of this manuscript. This study was financially supported by MARICE (Marine Chemical Ecology, an interdisciplinary research platform at the Faculty of Sciences, Göteborg University, Sweden) and by a grant from the foundation of Birgit and Birger Wåhlström to G.B.T. The experiments performed in the present study comply with current Swedish laws.

\section{LITERATURE CITED}

Barthel D, Wolfrath B (1989) Tissue sloughing in the sponge Halichondria panicea-a fouling organism prevents being fouled. Oecologia 78:357-360

Berntsson KM, Jonsson PR, Lejhall M, Gatenholm P (2000) Analysis of behavioural rejection of micro-textured surfaces and implications for recruitment by the barnacle Balanus improvisus. J Exp Mar Biol Ecol 251:59-83

Bingham BL, Young CM (1991) Influence of sponges on invertebrate recruitment: a field test of allelopathy. Mar Biol 109:19-26

Brock E, Nylund GM, Pavia H (2007) Chemical inhibition of barnacle larval settlement by the brown alga Fucus vesiculosus. Mar Ecol Prog Ser 337:165-174

Bullard SG, Whitlatch RB, Osman RW (2004) Checking the landing zone: Do invertebrate larvae avoid settling near superior spatial competitors? Mar Ecol Prog Ser 280: 239-247

Dahlström M, Mårtensson LGE, Jonsson PR, Arnebrant T, Elwing H (2000) Surface-active adrenoceptor compounds prevent the settlement of cyprid larvae of Balanus improvisus. Biofouling 16:191-203

Davis A, Targett N, McConnell O, Young C (1989) Epibiosis of marine algae and benthic invertebrates: natural products chemistry and other mechanisms inhibiting settlement and overgrowth. In: Scheuer PJ (ed) Bioorganic marine chemistry, Vol 3. Springer, Berlin, p 85-114

Dayton PK (1971) Competition, disturbance, and community organization: the provision and subsequent utilization of space in a rocky intertidal community. Ecol Monogr 41: 351-389

de Nys R, Steinberg PD (1999) Role of secondary metabolites from algae and seagrasses in biofouling control. In: Fin- german M, Nagabhushanam R, Thompson MF (eds) Recent advances in marine biotechnology, Vol 3. Science Publishers, Enfield, NH, p 223-244

de Nys R, Dworjanyn SA, Steinberg PD (1998) A new method for determining surface concentrations of marine natural products on seaweeds. Mar Ecol Prog Ser 162:79-87

Dobretsov S, Dahms HU, Qian PY (2004) Antilarval and antimicrobial activity of waterborne metabolites of the sponge Callyspongia (Euplacella) pulvinata: evidence of allelopathy. Mar Ecol Prog Ser 271:133-146

$>$ Dobretsov S, Dahms HU, Harder T, Qian PY (2006) Allelochemical defense against epibiosis in the macroalga Caulerpa racemosa var. turbinata. Mar Ecol Prog Ser 318: 165-175

Dworjanyn SA, de Nys R, Steinberg PD (2006) Chemically mediated antifouling in the red alga Delisea pulchra. Mar Ecol Prog Ser 318:153-163

$>$ Grosberg RK (1981) Competitive ability influences habitat choice in marine invertebrates. Nature 290:700-702

Harder TS, Qian PY (2000) Waterborne compounds from the green seaweed Ulva reticulata as inhibitive cues for larval attachment and metamorphosis in the polychaete Hydroides elegans. Biofouling 16:205-214

Harder T, Dobretsov S, Qian PY (2004) Waterborne polar macromolecules act as algal antifoulants in the seaweed Ulva reticulata. Mar Ecol Prog Ser 274:133-141

Harper MK, Bugni TS, Copp BR, James RD and others (2001) Introduction to the chemical ecology of marine natural products. In: McClintock JB, Baker BJ (eds) Marine chemical ecology. CRC Press, Boca Raton, FL, p 3-29

Hunt HL, Scheibling RE (1997) Role of early post-settlement mortality in recruitment of benthic marine invertebrates. Mar Ecol Prog Ser 155:269-301

Kubanek J, Whalen KE, Engel S, Kelly SR, Henkel TP, Fenical W, Pawlik JR (2002) Multiple defensive roles for triterpene glycosides from two Caribbean sponges. Oecologia 131: 125-136

Larsson AI, Jonsson PR (2006) Barnacle larvae actively select flow environment supporting post-settlement growth and survival. Ecology 87:1960-1966

$>$ Lee OO, Qian PY (2003) Chemical control of bacterial epibiosis and larval settlement of Hydroides elegans in the red sponge Mycale adherens. Biofouling 19:171-180

Littler MM, Littler DS (1999) Blade abandonment/proliferation: a novel mechanism for rapid epiphyte control in marine macrophytes. Ecology 80:1736-1746

Nylund GM, Cervin G, Hermansson M, Pavia H (2005) Chemical inhibition of bacterial colonization by the red alga Bonnemaisonia hamifera. Mar Ecol Prog Ser 302:27-36

Nylund GM, Gribben PE, de Nys R, Steinberg PD, Pavia H (2007) Surface versus whole-cell extracts: antifouling tests with seaweed metabolites. Mar Ecol Prog Ser 329:73-84

Paul NA, de Nys R, Steinberg PD (2006a) Chemical defence against bacteria in the red alga Asparagopsis armata: linking structure with function. Mar Ecol Prog Ser 306:87-101

Paul VJ, Puglisi MP, Ritson-Williams R (2006b) Marine chemical ecology. Nat Prod Rep 23:153-180

Pawlik JR (1992) Chemical ecology of the settlement of benthic marine invertebrates. Oceanogr Mar Biol Annu Rev 30:273-335

Schmitt TM, Hay ME, Lindquist N (1995) Constraints on chemically mediated coevolution: multiple functions for seaweed secondary metabolites. Ecology 76:107-123

Sjögren M, Göransson U, Johnsson AL, Dahlström M and others (2004) Antifouling activity of brominated cyclopeptides from the marine sponge Geodia barretti. J Nat Prod 67:368-372 
Steinberg PD, de Nys R (2002) Chemical mediation of colonization of seaweed surfaces. J Phycol 38:621-629

Steinberg PD, de Nys R, Kjelleberg S (2001) Chemical mediation of surface colonization. In: McClintock JB, Baker BJ (eds) Marine chemical ecology. CRC Press, Boca Raton, FL, p 355-387

Steinberg PD, de Nys R, Kjelleberg S (2002) Chemical cues for surface colonization. J Chem Ecol 28:1935-1951

Thompson JE (1985) Exudation of biologically-active metabolites in the sponge Aplysina fistularis. I. Biological evidence. Mar Biol 88:23-26

Thompson JE, Walker RP, Faulkner DJ (1985) Screening and bioassays for biologically-active substances from forty marine sponge species from San Diego, California, USA. Mar Biol 88:11-21

Editorial responsibility: Joseph Pawlik, Wilmington, North Carolina, USA
Walters LJ, Hadfield MG, Smith CM (1996) Waterborne chemical compounds in tropical macroalgae: positive and negative cues for larval settlement. Mar Biol 126:383-393

Welch JM, Rittschof D, Bullock TM, Forward RB Jr (1997) Effects of chemical cues on settlement behaviour of blue crab Callinectes sapidus postlarvae. Mar Ecol Prog Ser 154:143-153

Wikström SA, Pavia H (2004) Chemical settlement inhibition versus post-settlement mortality as an explanation for differential fouling of two congeneric seaweeds. Oecologia 138:223-230

Young CM, Chia FS (1981) Laboratory evidence for delay of larval settlement in response to a dominant competitor. Int J Invertebr Reprod 3:221-226

Submitted: March 6, 2007; Accepted: October 7, 2007 Proofs received from author(s): January 14, 2008 